\title{
The phenomenon of pregnancy - a psychological view
}

\author{
Artur Bjelica ${ }^{1,2}$, Nenad Cetkovic ${ }^{1,2}$, Aleksandra Trninic-Pjevic ${ }^{1,2}$, Ljiljana Mladenovic-Segedi1, 2 \\ ${ }^{1}$ Faculty of Medicine, University of Novi Sad, Serbia \\ ${ }^{2}$ Department of Obstetrics and Gynecology, Clinical Center of Vojvodina, Novi Sad, Serbia
}

\begin{abstract}
Pregnancy is a very specific and complex period in a woman's life. The accompanying changes are observed not only on the biological/physiological plane but also in her psychological and social functioning. Altered psychological functioning can occur from the very beginning to the end of pregnancy, including the postpartum period. During pregnancy, visible changes occur in the body's appearance, as well as in femininity, affections, and sexuality, whereas the woman's position and role are gaining new qualities. To a greater or lesser degree, every expectant mother experiences psychological ambivalence, frequent mood changes from exhaustion to exaltation, emotional disturbances, and/or mixed anxiety-depressive disorder. In addition, pregnancy causes a number of specific apprehensions concerning the course and outcome, which makes the woman particularly vulnerable and requires adequate treatment, depending on the adaptive capacities of her personality. Furthermore, from a psychosocial aspect, pregnancy could be considered a specific highly emotional state, which may be a potent stressor. Perinatal maternal stress can lead to different complications that may have far-reaching consequences for both somatic and psychic functioning of the newborn.
\end{abstract}

This review considers pregnancy as a complex psychological phenomenon and explores multiple changes in the woman's psychological functioning in both normal and psychologically complicated courses of pregnancy.

Key words: pregnancy, mental health, psychology

\section{INTRODUCTION}

In addition to the changes in somatic and physiological states, pregnancy causes changes on the psychological and social planes. Pregnancy, and especially the first one, is a powerful psychological experience. In the first pregnancy, women are faced not only with an entirely new sitution, but also enter a period which is crucial for their intense development as mothers. Pregnancy and motherhood represent an integration of the instictive pursuits and highest aspirations - to give birth to a child and be(come) a parent.

Pregnancy should be considered a complex bio-psycho-social phenomenon in which somatic changes are accompanied by the changes of psychological character and altered interactions with the social environment [1].

\section{PSYCHOLOGY OF PREGNANCY}

A pregnant woman is most certainly faced with her biological femininity, which influences her self-concept.
In addition, she experiences a number of specific apprehensions concerning the course and outcome of pregnancy. This makes her particularly vulnerable as she is conditioned by the adaptive capacities of her personality, lifestyle, and status in the social environment.

Psychoanalytically-oriented authors were the first to point out the complexity of psychological changes in pregnancy. These changes are related to the satisfaction of narcissistic needs and resumption of the conflicts dating from the early period of development, regressive tendencies, and anxiety. Thus pregnancy is considered an instinctual process which recapitulates infantile sexuality [2]. The first trimester is dominated by orality, which causes food cravings, nausea and vomiting, due to the attachment of the fetus inside the uterus. In the second trimester, the fetus shows greater personhood as anal trends become more prominent, which corresponds to the period of increased separation. Finally, the third trimester is characterized by

Corresponding author:

Artur Bjelica

Department of Obstetrics and Gynecology,

Clinical Center of Vojvodina, Faculty of Medicine, University of Novi Sad

Branimira Cosica 37, Novi Sad, Serbia

tel.: +38121 4899330;

e-mail: artur.bjelica@mf.uns.ac.rs 
phallic-aggressive wishes, associated with urethral issues and the woman's increased fears that she or the baby may die. Accompanying this libidinal regression, earlier modes of cognition are common during pregnancy. Ego regression distorts the woman's perception of reality, induces irrational beliefs and fears due to magical thinking associated with the primary process. Magical thinking occurs when "the person believes that his or her thoughts, words, or actions might, or will in some manner, cause or prevent a specific outcome in some way that defies the normal laws of cause and effect" [3]. Furthermore, this situation, with higher emotional fluctuations can provoke anxious trends with phobic and obsessive-compulsive preoccupations [4].

It is postulated that early infantile sexual fantasies and repressed memories of object-relations traumas combine with ubiquitous bodily fantasies to produce the 'Medea fantasy'. This is an unconscious conviction that sexual passion carries the risk of existential dependence on the love partner and possible abandonment by him. Women affected by this fantasy are convinced that they could not endure this, and react with lethally destructive impulses, constituting an existential danger to their selves, their love objects, and their children. It seems to them an imperative to forgo any creative unfolding of their femininity, and symbolically 'deaden' themselves [5].

Some women tend to consider their pregnancy and future motherhood as their 'raison d'être'. According to Helen Deutsch, organic obstructions are a consequence of the activity of the psychic apparatus in the sense of releasing tension. Nausea is a manifestation of all negative emotions accumulated through years, and vomiting is "a tendency of ejecting the fetus from the womb «, whereas overeating is »a tendency of retaining the fetus«. Deutsch considers that the first pregnancy is a borderline situation since it causes emotional ambivalence conditioned by the desire for motherhood on the one hand and the fact that an unborn child is a hindrance to her individual existence on the other [6].

Every pregnancy is accompanied by emotional, psychological, and cognitive changes. Buckwalter et al. observed certain concomitant changes in cognition and mood. During pregnancy and in a longer postpartal period it is possible to observe certain changes in the mood and a deficit in the function of verbal learning [7]. With the majority of women, pregnancy influences the attitude toward their selves, their whole environment and their future life. Each pregnancy places certain requirements on women for treating some specific fears related to pregnancy and delivery, and imposes requirements for adaptation to hormonal and physical changes. However, one's way of reacting to pregnancy is largely culture-conditioned. Namely, Margaret Mead was among the first to write about the cultural determinism of pregnancy-related symptomatology, as the majority of women fit into a culturally defined role [8]. In addition, of crucial importance is the personal conviction of the expectant mother and her reflections on pregnancy as a normal constituent part of her life, and not a transitional 'state of sickness'.

Many authors consider pregnancy a 'psychological burden'. The related states are frequent changes of mood, ranging from excitement to exaltation [9]. Furthermore, pregnancy is a period of significant anxiety, with symptoms that especially escalate in the third trimester [10].

Therefore, pregnancy can be understood as a state in which both the body and soul 'bear the burden', the state of alternately relieving and maintaining psychic tensions. The tension is caused either consciously or unconsciously, by the fear of loosing personal identity, feelings of uncertainty and loneliness, the fear of losing the child, or of delivery. Even nowadays, expectant mothers feel the primeval fear of dying during delivery. The term 'tokophobia' is related to a specific upset/anxious state with a phobic avoidance of pregnancy [11]. Primary tokophobia has its roots in adolescence, while the secondary one is a consequence of a traumatic delivery. Pregnant women with tokophobia suffer more often from 'hyperemesis gravidarum'. Their characteristics are: rejection of pregnancy, inability to establish emotional bonds with the fetus, intense fear of the forthcoming delivery, and postpartum depression. Some tokophobic women often require sterilization or vasectomy of the partner because of the intense fear of pregnancy. They are also under increased risk of post-traumatic stress disturbance [12].

Assuming that the labor pain is not caused only by the triad of anatomical, physiological, and neurological determinants, Whitburn concluded that it is a complex interaction of the mind, brain, body, and social environment, stressing that the pain is not always a signal of bodily disorders, but is in the domain of the conscious mind [13]. Pain is an individual and multifactorial experience influenced by culture, previous acquaintance/familiarity with pain, beliefs, moods, and the ability to cope [14]. The presence of the partner/husband may reduce peripartal pain and stress. The Bonapace Method takes advantage of this to control pain by breathing, relaxation, cognitive structuring, and hyperstimulation of acupressure trigger points, which can also improve labor progression [15]. The assessment of adult attachment can identify women at high risk of poorly coping with pain during childbirth. Women with an insecure attachment style report higher pain before starting patient-controlled epidural analgesia. Additionally, they require higher consumption of analgesic drugs [16].

Many experts think that pregnancy is a period of possible growth and development of the woman's personal potentials, leading to a new level of their integration. 
Similarly, Bibring and Valenstein describe pregnancy as a bio-psycho-social crisis which, under favorable conditions, can lead to personal maturity. The outcome has very important effects not only on the mother, but also on early emotional relations between the mother and the child [17].

The significance of participation of the husband/partner in pregnancy is expressed by the coinage 'pregnant couple'. The quality of this relationship is partly conditioned by the experience of the parents' relationship during childhood. A younger age, especially of females, poor partnership relations, and gender-role related stress, are all distress predictors which occur in the middle of pregnancy. Further, the partners' negative moods and their poor relationship can be prediction factors for postnatal distress [18]. During the wife's pregnancy the husband also experiences signs of something new and unknown, as he is going to be a novice in the role of father. In about $11-15 \%$ of the cases future fathers experience the 'Couvade syndrome', which is manifested as the loss of appetite, nausea, irritability, headaches, and sleep disturbances. In addition, some authors mention changes in sexual habits, fear, anxiety, and curiosity. The symptoms disappear after the wife's delivery [19].

A correlation has been established between depressive moods and parenthood and its dependence on the age at the moment of the first delivery. Becoming a parent at an early age may mean a poorer start in life, which can lead to a disturbance of the transition from adolescence to maturity, which in turn may have far-reaching consequences on the emotional stability of people. There are indications of the existence of a negative correlation between the age at the moment of the first delivery and depressive feelings, after making corrections for age, gender, minority affiliation, and education. The subjects that were under 23 at the moment of having the first child showed more signs of depression compared to those who had no parental status. The association between depression and age at the moment of the first delivery is monotonous for husbands and parabolic for wifes. Namely, women aged about 30 exhibited a lower level of depression. There are certain psychological benefits of postponing the first pregnancy, such as later marrige, higher education level, higher possibility of finding a job, less probable shortage of money, and a better mental health. However, the potential health consequences for women decrease the potential emotional benefits [20].

When considering the psychic changes occurring in pregnancy, it is necessary to tackle the issue of postpartal psychic disturbances. They are multidimensionally conditioned, with a predominance of psychosocial factors over hereditary ones. These disturbances are manifested as different forms of depressive reactions following delivery, or as the acute postpartum psychosis, with polymorphic symptomatology of a confusional-deliriant psychosis.
In addition to the unipolar postpartum major depression, bipolar disorder may also develop with a high risk of infanticide and suicide among the affected women [21].

Recent investigations of psychological issues in pregnancy also include neuroendocrine aspects. A number of animal studies clearly point to the influence of estrogen and progesterone in the initial expression of maternal behavior. First-time birthing rats spontaneously demonstrate maternal behavior, like retrieving, licking, crouching, nursing, and nest-building. Male rats and virgin females engage in these maternal actions only after constant exposure to pups for 5 to 7 days [22]. Human neuroimaging studies stress the importance of hormones like oxytocin and vasopressin and the hypothalmic-midbrain-limbic-paralimbic-cortical circuits of the brain in the early activation of maternal behavior [23]. Edelstein et al. examined the changes in the levels of testosterone, cortisol, estradiol, and progesterone in first-time expectant couples. Female subjects showed large prenatal increases in all investigated hormones, while men showed significant prenatal declines in testosterone and estradiol, with no changes in cortisol and progesterone levels [24].

\section{PSYCHOPATHOLOGICAL ASPECTS OF PREGNANCY}

Numerous investigations indicate a significant role of prenatal maternal stress in the occurrence of pre-term delivery and newborn's low weight [25]. It has also been pointed out that the role of stress in the appearance of pregnancy-induced hypertension is a very serious problem in perinatology [26]. Presently, pregnancy is understood as a maturation crisis, which may be characterized by the phases of regression, weakening of mental defence mechanisms, self-image transformation, and potential conflict with one's own femininity. Such pregnancies are 'psychologically risky', and are usually complicated by some somatic symptoms such as intense nausea and vomiting, induced hypertension, miscarriage, and pre-term delivery. This opinion is also related to the modern approach to studying different pregnancy-related symptoms, which include important evaluations of potential psychosocial variables [27]. From this psychosocial approach, pregnancy can be understood as a specific highly emotional state, which may be a potent stressor.

Studies on prenatal psychology show that stress and emotional status of women during pregnancy may have significant consequences for the status of the fetus. This new discipline advocates the need to ensure good prenatal conditions, in order to provide an optimal state for the postnatal development of the child. It is believed that tensions, anxiety, depressive episodes, long-running marital disagreements, financial problems, etc., may have unfavorable effects on the subsequent psychic development of the child. 
It is postulated that stress begins in the mother's womb. The fetus'learns'about the mother's emotional changes through hormonal fluctuations. The mother's neurosis can create a chaos in hormone secretion, and hormonal disturbances may cause long-lasting damages to the fetus. Depending on the circumstances, these disturbances are also reflected on the child's mental state, which determines whether the child will be aggressive or passive. Field et al. found that mothers exhibiting high-rage episodes during pregnancy had high prenatal levels of cortisol and adrenaline and low levels of dopamine and serotonine. Their newborns also had high levels of cortisol and low levels of dopamine, and showed disturbances in sleep rhythm. The existence of the relative right-side frontal EEG activation and a low vagus were also noticeable in both mothers and newborns [28].

Pregnant women reporting 'high psychosocial levels' of stress are at approximately 25-60\% higher risk of preterm birth compared to those reporting 'low stress levels'. Maternal depression can have some far-reaching consequences on the emotional and behavioral status of the child. Thus, depression symptoms, both in the prenatal and postpartum periods, are associated with higher child dysregulation up to the age of 7 [29].

A pregnant woman is psychologically vulnerable and needs increased social and partner support. Numerous studies prove that social support significantly improves the quality of the birth experience, and potentially reduces the risk of obstetrical complications. In some cases, the partners' relations are disturbed during pregnancy. Psychological aggression may have harmful effects on both partners, sometimes exceeding those of physical aggression. The transition to parenthood is a time when relationship satisfaction often declines, and a psychological aggression trajectory may occur during this period [30].

Although it is obvious that pregnant women should be given social support, it is difficult to define how exactly we should understand this concept. Cobb gave a multidimensional definition of this notion, stating that it is "information leading a subject to believe that he or she is cared for, loved, esteemed and valued, and that he or she belongs to a network of communication and obligation" [31]. Many researchers confirm a positive impact of neighborhood, social support, and avoidance coping on depression symptoms in pregnant women, evidenced as the understanding and development of positive emotions towards them, which help prevent postpartal depressive episodes [32].

Inadequate social support or its lack during pregnancy, combined with stressful events and strong disturbances of emotional stability, can lead to complications during pregnancy and delivery, and influence the fetal condition. However, social support should not be considered significant for stress reduction in special, risky-type pregnant women alone, but a measure which stimulates the engagement of personal potentials aiming at a successful course of pregnancy and delivery itself. Such an approach is particularly important having in mind investigation results which point out the existence of an association between perinatal complications and later risk for psychiatric disturbances, especially in the case of hereditary predispositions [33].

A special problem is pseudocyesis (synonyms: false pregnancy, phantom pregnancy, hysterical pregnancy) - the appearance of symptoms and clinical signs associated with pregnancy in non-pregnant women. False pregnancy is caused by endocrinological changes in the body, leading to physical changes similar to those during pregnancy. Such women may have an increased sympathetic nervous system activity; dysfunction of the central nervous system catecholaminergic pathways involved in the regulation of hormone secretion from adenohypophysis, and decreased steroid feedback inhibition of GnRH. These neuroendocrine disorders can cause hypo/amenorrhea, galactorrhea, hyperprolactinemia, abdominal distension and apparent fetal movements and pains similar to labor pains at the expected date of delivery [34].

Another important pathopsychological issue in pregnancy is pregorexia. It refers to "a woman's drive to control pregnancy weight gain through extreme dieting and exercise". Such women are simultaneously anorexic and bulimic. Despite the fact that many obstetricians do not recognize pregorexia, the associated behavior is real, and can have a negative impact on fetal health. Still, pregorexia is exceedingly rare. Far more pregnant women gain too much rather than too little weight. 'Good candidates' for pregorexia are women which excessively care about their weight gain and body image during pregnancy. The risk of pregorexia may be higher for women with a history of eating disorders and for those having a weak social support system. The warning signs of pregorexia are: talking about pregnancy as if it were not real, skipping meals and focusing on calorie counts, and excessive exercise [35].

\section{REFERENCES}

1. Bjelica A, Kapor-Stanulovic P. Pregnancy as a psychological event. Med Pregl. 2004; 57(3-4): 144-148, doi: 10.2298/mpns0404144b, indexed in Pubmed: 15462597.

2. Kestenberg J. On the Development of Maternal Feelings in Early Childhood. Psychoanal Study Child. 2017; 11(1): 257-291, doi: 10.1080/00797308.1956.11822788.

3. American Psychiatric Association. Diagnostic and Statistical Manual of Mental Disorders. Fourth edition, text revision. DC: American Psychiatric Association, Washington 2000.

4. Leon I. Psychology of Reproduction: Pregnancy, Parenthood, and Parental Ties. Glob libr women's med. 2008, doi: 10.3843/glowm.10419.

5. Leuzinger-Bohleber M. The'Medea fantasy'. An unconscious determinant of psychogenic sterility. Int J Psychoanal. 2001; 82(Pt 2): 323-345, doi: 10.1516/0020757011600849, indexed in Pubmed: 11341065.

6. Deutsch H. The psychology of women. Grune Straton, New York 1944. 
7. Buckwalter JG, Buckwalter DK, Bluestein BW, et al. Pregnancy and post partum: changes in cognition and mood. Prog Brain Res. 2001; 133: 303-319, indexed in Pubmed: 11589139.

8. Mead M. Male and female: A study of the sexes in a changing world. Morrow, New York 1949.

9. Lips HM. A longitudinal study of the reporting of emotional and somatic symptoms during and after pregnancy. Soc Sci Med. 1985; 21(6): 631-640, doi: 10.1016/0277-9536(85)90202-3, indexed in Pubmed: 4059947.

10. Lubin B, Gardener SH, Roth A. Mood and somatic symptoms during pregnancy. Psychosom Med. 1975; 37(2): 136-146, doi: 10.1097/00006842197503000-00004, indexed in Pubmed: 1135360.

11. Hofberg K, Brockington I. Tokophobia: an unreasoning dread of childbirth. A series of 26 cases. Br J Psychiatry. 2000; 176: 83-85, indexed in Pubmed: 10789333.

12. Forray A, Mayes LC, Magriples U, et al. Prevalence of post-traumatic stress disorder in pregnant women with prior pregnancy complications. J Matern Fetal Neonatal Med. 2009; 22(6): 522-527, doi: 10.1080/14767050902801686, indexed in Pubmed: 19488936.

13. Whitburn LY. Labour pain: from the physical brain to the conscious mind. J Psychosom Obstet Gynaecol. 2013; 34(3): 139-143, doi: 10.3109/0167482X.2013.829033, indexed in Pubmed: 23952172

14. Ogboli-Nwasor $\mathrm{E}$, Adaji $\mathrm{Se}$, Bature $\mathrm{Sb}$, et al. Pain relief in labor: a survey of awareness, attitude, and practice of health care providers in Zaria, Nigeria. J Pain Res. 2011; 4: 227-232, doi: 10.2147/JPR.S21085, indexed in Pubmed: 21887120.

15. Bonapace J, Chaillet N, Gaumond I, et al. Evaluation of the Bonapace Method: a specific educational intervention to reduce pain during childbirth. J Pain Res. 2013; 6:653-661, doi: 10.2147/JPR.S46693, indexed in Pubmed: 24043953

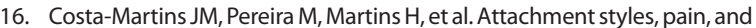
the consumption of analgesics during labor: a prospective observational study. J Pain. 2014; 15(3): 304-311, doi: 10.1016/j.jpain.2013.12.004, indexed in Pubmed: 24393700.

17. Bibring GL, Valenstein AF. Psychological aspects of pregnancy. Clin Obstet Gynecol. 1976; 19(2): 357-371, doi: 10.1097/00003081-19760600000010, indexed in Pubmed: 1277609.

18. Furukawa TA, Hori $\mathrm{S}$, Azuma $\mathrm{H}$, et al. Parents, personality or partner? Correlates of marital relationships. Soc Psychiatry Psychiatr Epidemiol. 2002; 37(4): 164-168, doi: 10.1007/s001270200010, indexed in Pubmed: 12027242.

19. Kazmierczak M, Kielbratowska B, Pastwa-Wojciechowska B. Couvade syndrome among Polish expectant fathers. Med Sci Monit. 2013; 19 : 132-138, doi: 10.12659/MSM.883791, indexed in Pubmed: 23425940.

20. Mirowsky J, Ross CE. Depression, parenthood, and age at first birth. Soc Sci Med. 2002; 54(8): 1281-1298, doi: 10.1016/s0277-9536(01)00096-x, indexed in Pubmed: 11989963.

21. Khan M, Sharma V. Post-partum depressive episodes and bipolar disorder. Lancet. 2015; 385(9970): 771-772, doi: 10.1016/S01406736(15)60433-0, indexed in Pubmed: 25752172
22. Kinsley $\mathrm{CH}$. Developmental psychobiological influences on rodent parental behavior. Neurosci Biobehav Rev. 1994; 18(2): 269-280, doi: 10.1016/0149-7634(94)90029-9, indexed in Pubmed: 7914687.

23. Brunton PJ, Russell JA. The expectant brain: adapting for motherhood. Nat Rev Neurosci. 2008; 9(1): 11-25, doi: 10.1038/nrn2280, indexed in Pubmed: 18073776.

24. Edelstein RS, Wardecker BM, ChopikWJ, et al. Prenatal hormones in first-time expectant parents: Longitudinal changes and within-couple correlations. Am J Hum Biol. 2015; 27(3): 317-325, doi: 10.1002/ajhb.22670, indexed in Pubmed: 25504668.

25. Staneva A, Bogossian F, Pritchard M, et al. The effects of maternal depression, anxiety, and perceived stress during pregnancy on preterm birth: A systematic review. Women Birth. 2015; 28(3): 179-193, doi: 10.1016/j. wombi.2015.02.003, indexed in Pubmed: 25765470.

26. Bjelica A. [Pregnancy as a stressful life event and strategies for coping with stress in women with pregnancy-induced hypertension]. Med Pregl. 2004; 57(7-8): 363-368, doi: 10.2298/mpns0408363b, indexed in Pubmed: 15626294.

27. Rodriguez A, Bohlin G, Lindmark G. Symptoms across pregnancy in relation to psychosocial and biomedical factors. Acta Obstet Gynecol Scand. 2001; 80(3): 213-223, doi: 10.1080/j.1600-0412.2001.080003213.x, indexed in Pubmed: 11207486.

28. Field $T$, Diego $M$, Hernandez-Reif $M$, et al. Prenatal anger effects on the fetus and neonate. J Obstet Gynaecol. 2002; 22(3): 260-266, doi: 10.1080/01443610220130526, indexed in Pubmed: 12521495.

29. Pina-Camacho L, Jensen SK, Gaysina D, et al. Maternal depression symptoms, unhealthy diet and child emotional-behavioural dysregulation. Psychol Med. 2015;45(9): 1851-1860, doi: 10.1017/S0033291714002955, indexed in Pubmed: 25524365.

30. Sotskova A, Woodin EM, Gou LH, et al. Hostility, flooding, and relationship satisfaction: Predicting trajectories of psychological aggression across the transition to parenthood. Aggress Behav. 2014 [Epub ahead of print]; 41(2): 134-148, doi: 10.1002/AB.21570, indexed in Pubmed: 25503086.

31. Cobb S. Presidential Address-1976. Social support as a moderator of life stress. Psychosom Med. 1976; 38(5): 300-314, doi: 10.1097/00006842197609000-00003, indexed in Pubmed: 981490.

32. Giurgescu C, Zenk SN, Templin TN, et al. The Impact of Neighborhood Environment, Social Support, and Avoidance Coping on Depressive Symptoms of Pregnant African-American Women. Womens Health Issues. 2015; 25(3): 294-302, doi: 10.1016/j.whi.2015.02.001, indexed in Pubmed: 25840930.

33. Norbeck JS, Tilden VP. Life stress, social support, and emotional disequilibrium in complications of pregnancy: a prospective, multivariate study. J Health Soc Behav. 1983; 24(1): 30-46, doi: 10.2307/2136301, indexed in Pubmed: 6853997.

34. Tarín JJ, Hermenegildo C, García-Pérez MA, et al. Endocrinology and physiology of pseudocyesis. Reprod Biol Endocrinol. 2013; 11: 39, doi: 10.1186/1477-7827-11-39, indexed in Pubmed: 23672289.

35. Mathieu J. What is pregorexia? J Am Diet Assoc. 2009; 109(6): 976-979, doi: 10.1016/j.jada.2009.04.021, indexed in Pubmed: 19465173. 